\title{
SOD2 gene Val16Ala polymorphism is associated with macroalbuminuria in Mexican Type 2 Diabetes patients: a comparative study and meta-analysis
}

Iván de Jesús Ascencio-Montiel ${ }^{1 \dagger}$, Esteban J Parra ${ }^{2 \dagger}$, Adán Valladares-Salgado ${ }^{1}$, Jaime H Gómez-Zamudio ${ }^{1}$, Jesús Kumate-Rodriguez ${ }^{3}$, Jorge Escobedo-de-la-Peña ${ }^{4}$ and Miguel Cruz ${ }^{1^{*}}$

\begin{abstract}
Background: Several studies in type 2 diabetes patients have shown significant associations between the SOD2 gene Val16Ala polymorphism and albuminuria, but this association has not been explored in the Mexican population.

Methods: We evaluated the association between the SOD2 gene Val16Ala polymorphism (rs4880) and macroalbuminuria in a sample of 994 unrelated Mexican type 2 diabetes patients. The study included 119 subjects with urinary albumin $>300 \mathrm{mg} / \mathrm{dL}$ and 875 subjects with urinary albumin $\leq 30 \mathrm{mg} / \mathrm{dL}$. Genotyping of the SOD2 gene Val16Ala SNP was carried out with Real-Time Polymerase Chain Reaction (RT-PCR).

Results: The frequency of the $\Pi$ genotype was $6.7 \%$ higher in participants with macroalbuminuria than in the normoalbuminuria group (16.8\% vs. 10.1\%). Using a logistic regression analysis, we observed that individuals with the CC genotype had significantly lower risks of macroalbuminuria than those with the $\Pi$ genotype (OR=0.42, $p=0.034)$. We carried out a meta-analysis combining our data with data from four previous studies and estimated an odds ratio $(95 \% \mathrm{Cl})$ for the $\mathrm{C}$ allele (with respect to the reference $T$ allele) of $0.65(0.52-0.80, \mathrm{p}<0.001)$.
\end{abstract}

Conclusions: A significant association was found between the SOD2 Val16Ala polymorphism and macroalbuminuria in a sample of Mexican type 2 diabetes patients.

Keywords: Mexicans, Macroalbuminuria, SOD2, Type 2 diabetes, Val16Ala polymorphism

\section{Background}

Diabetic nephropathy (DN) is the leading cause of chronic kidney disease [1]. However, the risk factors for DN have not been clearly established [2] and the pathogenesis of the disease remains unclear. There is evidence indicating that oxidative stress is associated with renal damage [3]. Macroalbuminuria is a predictor of $\mathrm{DN}$, cardiovascular morbidity and mortality [4-6].

Superoxide dismutase 2 (SOD2), also known as manganese superoxide dismutase (MnSOD), is one of the major

\footnotetext{
* Correspondence: mcruzl@yahoo.com

${ }^{\dagger}$ Equal contributors

'Biochemistry Research Unit, Hospital de Especialidades, Centro Médico

Nacional "Siglo XXI", Instituto Mexicano del Seguro Social, Mexico DF, Mexico Full list of author information is available at the end of the article
}

antioxidant defense systems against mitochondrial superoxide radicals [7]. The Val16Ala non-synonymous polymorphism (rs4880) in the SOD2 gene has been predicted to cause a conformational change in the target sequence, from a partial alpha-helix in the Ala-variant (coded by the $\mathrm{C}$ allele) to a beta-sheet in the Val-variant (coded by the $\mathrm{T}$ allele), which induces a 30-40\% decrease in SOD2 activity due less efficient transport of the protein into the mitochondrial matrix $[8,9]$.

Population differences in the incidence and progression of renal diseases have been described previously [10,11]. Native Americans, Hispanics and Mexicans have higher risk to develop DN in comparison with Europeans [12,13]. Contemporary Mexicans are an admixed population with genetic background derived from indigenous Mexican

\section{Biomed Central}


groups, Europeans and West Africans. For example, in a recent study in Mexico City, the relative Native American (NAM), European (EUR) and African (AFR) contributions were estimated as 65,30 and $5 \%$, respectively [14].

Several studies in type 2 diabetes (T2D) patients of Japanese, Korean and Chinese origin [15-18], as well as a meta-analysis [19], have shown significant associations between the SOD2 gene Val16Ala polymorphism and albuminuria, but this association has not been explored in the Mexican population. The aim of the study was to assess the association of the SOD2 gene Val16Ala polymorphism with macroalbuminuria in a sample of T2D patients from Mexico City.

\section{Methods}

\section{Ethics statement}

The project was approved by the 3609 Local Ethics Committee of the National Institute of Social Security (IMSS) according to the declaration of Helsinki. Written informed consent was obtained from each participant.

\section{Study group}

The study included 994 unrelated Mexican T2D patients recruited from primary care clinics of the IMSS, in Mexico City, between 2008 and 2010. Diabetes diagnosis was done according to the American Diabetes Association criteria, i.e. fasting plasma glucose $\geq 7.0$ $\mathrm{mmol} / \mathrm{l}$ or OGTT $\geq 11.1 \mathrm{mmol} / \mathrm{l}$ for the $2 \mathrm{~h}$ sample [20]. Albuminuria was determined in spot urinary samples by nephelometric immunoassay. Participants with macroalbiminuria $(\mathrm{N}=119)$ had urinary albumin $>300$ $\mathrm{mg} / \mathrm{dL}$, while normoalbuminuria $(\mathrm{N}=875)$ was defined as urinary albumin $\leq 30 \mathrm{mg} / \mathrm{dL}$ [21]. None of the participants showed any evidence of urinary tract infection, hematuria, acute febrile illness, acute heart failure or vigorous exercise, based on clinical examination and general urine testing. Data on age, gender, duration of T2D, body mass index (BMI) and systolic and diastolic blood pressure, previous diagnosis of hypertension, and hypertension treatment with angiotensin converting enzyme (ACE) or angiotensin receptor blockers (ARB) were also available for each participant. We also measured fasting glucose, glycated hemoglobin (Hb1Ac), LDL, HDL, and total cholesterol as well as triglycerides.

\section{DNA isolation}

DNA was extracted from peripheral blood using the QIAamp (Qiagen, Hilden, Germany) kit following the manufacturer's recommendations. DNA concentration was measured by optical density (VICTOR3 1420 spectrophotometer Perkin-Elmer, Massachusetts, USA), and integrity by electrophoresis in $0.8 \%$ agarose gels stained with ethidium bromide (Gel Doc 2000, BIORAD, California, USA).

\section{SOD2 gene Val16Ala polymorphism (rs4880) genotyping}

The SOD2 gene Val16Ala polymorphism was genotyped with RT-PCR, using the TaqMan ${ }^{\star}$ SNP Genotyping Assay (Applied Biosystems, California, USA).

\section{Ancestry estimation}

Individual admixture proportions were available for 386 out of the 875 participants with normoalbuminuria, and for 53 of 119 subjects in the macroalbuminuria group. For these individuals, Native American, European and West African contributions were estimated with the program ADMIXTURE [22], using a genome-wide panel of approximately 37,000 Ancestry Informative Markers (AIMs). These 37,000 AIMs were present in both the Affymetrix Genome-Wide Human SNP array 5.0 and the Axiom LAT Genome-Wide Human Array (Affymetrix, Santa Clara, CA, USA), which were used for high-density genotyping of the samples in an unrelated study [23].

\section{Statistical analysis}

Differences between groups were assessed using t-Student and chi-square tests for numerical and categorical variables, respectively. Deviations from the Hardy-Weinberg proportions were evaluated using an exact test (available at http://ihg.gsf.de/cgi-bin/hw/hwa1.pl).

In order to test if the SOD2 gene Val16Ala polymorphism was associated with macroalbuminuria, we used a logistic regression model including as covariates sex, duration of $\mathrm{T} 2 \mathrm{D}$, body mass index, systolic blood pressure, diastolic blood pressure, current and previous smoking, HbA1c, total cholesterol, HDL cholesterol, LDL cholesterol, previous diagnosis of hypertension and hypertension treatment with ACE or ARB, which showed significant differences between groups in our preliminary univariate analyses. The effect of the SOD2 gene Val16Ala polymorphism was tested using an unconstrained genetic model, where the odds ratios for the CC and CT genotypes were estimated independently, using the TT homozygote, which has been associated with lower SOD2 activity, as the reference genotype. In addition to the aforementioned analysis, we carried out two additional logistic regression analyses: one for the subset of the samples for which individual ancestry information was available, and another using normoalbuminuric subjects with more than 10 years of duration of T2D. The goal of these additional analyses was to determine if the association of the SOD2 gene Val16Ala polymorphism with macroalbuminuria could be driven by population stratification (e.g. differences in ancestry between normoalbuminuria and macroalbuminuria groups) or T2D duration. Finally, an inverse variance meta-analysis including this study as well as previously published studies 
[15-18] was carried out with the software Epidat Version 3.1 (available at: http://www.sergas.es/MostrarContidos_N3_T01. aspx?IdPaxina=62715).

\section{Results}

\section{Demographic and biochemical characteristics of} study groups

A total of 119 participants with macroalbuminuria and 875 with normoalbuminuria were included in the study. Table 1 shows the clinical characteristics of participants by albuminuria group. With respect to the normoalbuminuric subjects, the group of macroalbuminuric participants included more males, had higher proportions of individuals diagnosed with hypertension and receiving hypertension treatment, had longer duration of T2D, higher systolic and diastolic blood pressure, higher HbA1c, higher total cholesterol, HDL-cholesterol and LDL-cholesterol, lower body mass index and a lower proportion of smokers. There were no significant differences in age, fasting glucose, and triglycerides between groups.

\section{Association of the SOD2 gene Val16Ala polymorphism with macroalbuminuria}

Table 2 shows the allele and genotype frequencies of the SOD2 gene Val16Ala polymorphism in the comparison groups. There were no significant deviations from Hardy-Weinberg proportions in the normoalbuminuria or macroalbuminuria groups. The frequency of the $\mathrm{T}$ allele was higher in the macroalbuminuria group than in the normoalbuminuria group $(41.6 \%$ vs. $32.9 \%)$. With respect to the genotypes, the frequency of the TT genotype was $6.7 \%$ higher in the participants with macroalbuminuria than in the normoalbuminuric subjects $(16.8 \%$ vs. $10.1 \%)$. The effect of the SOD2 gene Val16Ala polymorphism on macroalbuminuria was evaluated using a logistic regression model including sex, duration of T2D, body mass index, systolic blood pressure, diastolic blood pressure, current or previous smoking, HbA1c, total cholesterol, HDLcholesterol, LDL-cholesterol, previous diagnosis of hypertension and hypertension treatment as covariates (all these variables were significantly associated with macroalbuminuria in our preliminary univariate analyses). Table 3 shows the OR estimates for all the variables showing significance in the logistic regression analysis. Using an unconstrained genetic model, the genotypes $\mathrm{CT}$ and $\mathrm{CC}$ had lower odds ratios for macroalbuminuria than the reference TT genotype (CT: OR $0.67, \mathrm{p}=0.308$; $\mathrm{CC}: \mathrm{OR}=0.42, \mathrm{p}=0.034$ ). This analysis did not include in the model individual ancestry proportions, which was not available for all the participants. Restricting our attention to the subset of the samples with information on individual ancestry proportions, we observed that macroalbuminuria subjects had a lower Native American ancestry mean than normoalbuminuria group $(0.597 \pm 0.027$ vs. $0.663 \pm 0.009, \mathrm{p}=0.012)$ (Figure 1$)$. The odds ratios for the $\mathrm{CT}$ and $\mathrm{CC}$ genotypes in the logistic regression analysis incorporating Native American ancestry as a covariate were overly similar to those observed for the full sample, although the p-values are weaker due to the reduced sample size $(\mathrm{CT}$ : $\mathrm{OR}=0.59, \mathrm{p}=0.400, \mathrm{CC}$ :

Table 1 Characteristics of T2D subjects by the presence of macroalbuminuria

\begin{tabular}{|c|c|c|c|}
\hline Characteristic & Macro albuminuria & Normo albuminuria & $P$ \\
\hline$n$ & $119(12.0)$ & $875(88.0)$ & \\
\hline Male/female & $73 / 46$ & $271 / 604$ & $<0.001$ \\
\hline Age (years) & $58.2 \pm 11.2$ & $57.2 \pm 9.5$ & NS \\
\hline Duration of T2D (years) & $17.3 \pm 9.8$ & $7.2 \pm 6.6$ & $<0.001$ \\
\hline Body mass index $\left(\mathrm{kg} / \mathrm{m}^{2}\right)$ & $28.4 \pm 4.6$ & $29.4 \pm 4.9$ & 0.027 \\
\hline Systolic blood pressure (mmHg) & $136.9 \pm 20.2$ & $125.7 \pm 18.3$ & $<0.001$ \\
\hline Diastolic blood pressure $(\mathrm{mmHg})$ & $85.8 \pm 12.1$ & $78.8 \pm 9.5$ & $<0.001$ \\
\hline Current or previous smoking/no smoking & $38 / 81$ & $418 / 457$ & 0.001 \\
\hline Fasting glucose (mmol/L) & $9.07 \pm 4.43$ & $8.8 \pm 3.65$ & NS \\
\hline $\mathrm{HbA1c}(\%)$ & $8.8 \pm 3.4$ & $7.48 \pm 2.81$ & $<0.001$ \\
\hline Total cholesterol (mmol/L) & $5.50 \pm 1.86$ & $5.12 \pm 1.11$ & 0.001 \\
\hline HDL cholesterol (mmol/L) & $1.14 \pm 0.37$ & $1.05 \pm 0.36$ & 0.015 \\
\hline LDL cholesterol (mmol/L) & $3.64 \pm 1.4$ & $3.15 \pm 0.9$ & $<0.001$ \\
\hline Triglycerides (mmol/L) & $2.67 \pm 1.89$ & $2.43 \pm 1.74$ & NS \\
\hline Previous diagnosis of hypertension yes/no & $64 / 55$ & $353 / 522$ & 0.005 \\
\hline Hypertension treatment with ACE or ARB yes/ no & $52 / 67$ & $245 / 630$ & $<0.001$ \\
\hline
\end{tabular}

Data is shown as number (\%) or average \pm standard deviation. $\mathrm{X} 2$ test or t-Student test $\mathrm{P}$ value. NS not significant, $A C E$ Angiotensin Converting Enzyme, $A R B$ Angiotensin receptor blockers. 
Table 2 Distribution of the SOD2 gene Val16Ala polymorphism among subjects

\begin{tabular}{|c|c|c|c|c|c|c|c|c|}
\hline \multirow[b]{2}{*}{ Gene } & \multirow[b]{2}{*}{ Polymorphism } & \multirow[b]{2}{*}{ Status } & \multicolumn{2}{|l|}{ Allele } & \multicolumn{3}{|c|}{ Genotype } & \multirow[b]{2}{*}{$P_{H W}$} \\
\hline & & & $T$ & $\mathrm{C}$ & $\pi$ & $\mathrm{CT}$ & $\mathrm{CC}$ & \\
\hline \multirow[t]{2}{*}{ SOD2 } & A16V & Macroalbuminuria & $99(41.6)$ & 139(58.4) & $20(16.8)$ & $59(49.6)$ & $40(33.6)$ & 0.650 \\
\hline & $C>T$ & Normoalbuminuria & $576(32.9)$ & $1174(67.1)$ & $88(10.1)$ & $400(45.7)$ & $387(44.2)$ & 0.320 \\
\hline
\end{tabular}

$\mathrm{P}_{\text {Hw: }}$ Hardy-Weinberg equilibrium exact $\mathrm{P}$ value. Data is shown as number (\%).

$\mathrm{OR}=0.31, \mathrm{p}=0.081$ ) (Figure 1). Additionally, the odds ratios for the $\mathrm{CT}$ and $\mathrm{CC}$ genotypes in the logistic regression analysis using normoalbuminuria subjects with more than 10 years of duration of T2D was quite similar (CT: OR 0.45, $\mathrm{p}=0.077$; $\mathrm{CC}: \mathrm{OR}=0.24, \mathrm{p}=0.002$ ).

\section{Meta-analysis with other available studies}

We carried out an inverse variance meta-analysis including our study and four additional studies for which genotype data are available. We report the results using an allele model ( $\mathrm{C}$ vs. $\mathrm{T}$ ), but other models (e.g. codominant or dominant TT vs. CC/CT) give consistent results. Table 4 reports the genotype and allele frequencies in the comparison groups, odds ratios and corresponding p-values for each study. There was not evidence of significant heterogeneity between studies $(\mathrm{Q}=3.28, \mathrm{p}=0.512)$, so we report here the results of the fixed effects meta-analysis. A forest plot with the estimates of odds ratios and 95\% confidence intervals (CI) for individual studies, as well as the combined odds ratios and CI based on fixed effects and random effects models, is shown in Figure 2. The results of the meta-analysis are significant, with an odds ratio $(\mathrm{CI})$ of $0.65(0.52-0.80, \mathrm{p}<0.001)$ for the fixed effects model. A sensitivity analysis excluding one study at a time indicates that the results of the meta-analysis are quite robust, with estimates of the odds ratios ranging from 0.52 to 0.80 ).

Table 3 Results of the logistic regression analysis of the SOD2 gene Val16Ala polymorphism and macroalbuminuria

\begin{tabular}{lll}
\hline Variable & OR $(\mathbf{9 5} \% \mathbf{C l})$ & $\boldsymbol{P}$ \\
\hline Male sex & $4.26(2.41-7.53)$ & $<0.001$ \\
Duration of T2D (years) & $1.14(1.10-1.17)$ & $<0.001$ \\
Diastolic blood pressure (mmHg) & $1.06(1.03-1.09)$ & $<0.001$ \\
Current or previous smoking & $0.41(0.23-0.71)$ & 0.002 \\
HbA1c (\%) & $1.15(1.05-1.25)$ & 0.002 \\
LDL cholesterol (mmol/L) & $1.99(1.29-3.10)$ & 0.002 \\
rs4880 & & \\
CT genotype & & NS \\
CC genotype & $0.67(0.31-1.45)$ & 0.034 \\
\hline
\end{tabular}

Logistic regression analysis including sex, duration of T2D, body mass index, systolic blood pressure, diastolic blood pressure, current and previous smoking, HbA1c, total cholesterol, HDL cholesterol, LDL cholesterol, previous diagnosis of hypertension, hypertension treatment with ACE or ARB, and the SOD2 gene Val16Ala polymorphism genotype. ${ }^{1} T$ is the reference genotype.

\section{Discussion}

Diabetic nephropathy is an important public health problem in Mexico. DN is the leading cause of end stage renal disease in adults and is responsible for approximately $75 \%$ of the total costs associated with the treatment of diabetic complications [24]. Previous research has indicated that there are population differences in the risk of developing end stage renal disease, which is significantly higher in African Americans, Asians and Latinos, relative to individuals of European ancestry [10]. However, the ultimate reasons for these prevalence differences have not been fully elucidated. Many hypotheses have been proposed to explain the development of diabetes complications, including $\mathrm{DN}$. One of the hypotheses is that oxidative stress plays a major role in the pathogenesis of diabetes complications [25]. For this reason, it is important to explore the potential effect of polymorphisms located within the genes coding for antioxidant enzymes, such as the SOD2 gene, on DN risk. A number of studies have focused on the SOD2 gene Val16Ala polymorphism, which is a nonsynonymous polymorphism that has been associated with $\mathrm{DN}$ in several populations. However, although polymorphisms in the ACE [26] and TGF- $\beta$ [27] genes have been previously associated with $\mathrm{DN}$ in the Mexican population, to our knowledge, the association between the SOD2 gene Val16Ala polymorphism and macroalbuminuria has not been yet studied in Mexico.

We genotyped the SOD2 gene Val16Ala polymorphism in 994 T2D patients: 119 individuals with macroalbuminuria and 875 normoalbuminuric subjects. In a logistic regression model incorporating other relevant covariates, the CT and $\mathrm{CC}$ genotypes had lower odds ratios than the reference TT genotype (CT: OR 0.67, $\mathrm{p}=0.308$; $\mathrm{CC}$ : $\mathrm{OR}=0.42, \mathrm{p}=0.034$ ). Given the different odd ratios observed for the $\mathrm{CT}$ and $\mathrm{CC}$ genotypes, a codominant model (CC vs. CT vs. TT) seems to provide the best fit to the data. Using a dominant model, instead of an unconstrained model, the $\mathrm{CC}+\mathrm{CT}$ genotypes had an OR=0.55 ( $\mathrm{p}=0.026)$, with respect to the TT genotype.

To our knowledge, ours is the largest study to date evaluating the association of the SOD2 gene Val16Ala polymorphism with macroalbuminuria. Our results are consistent with a growing number of studies in different population groups [15-19], and combining our study with previously available data provides strong support for the hypothesis that the SOD2 Val16Ala C allele, which codes for the amino acid alanine, confers a protective effect 


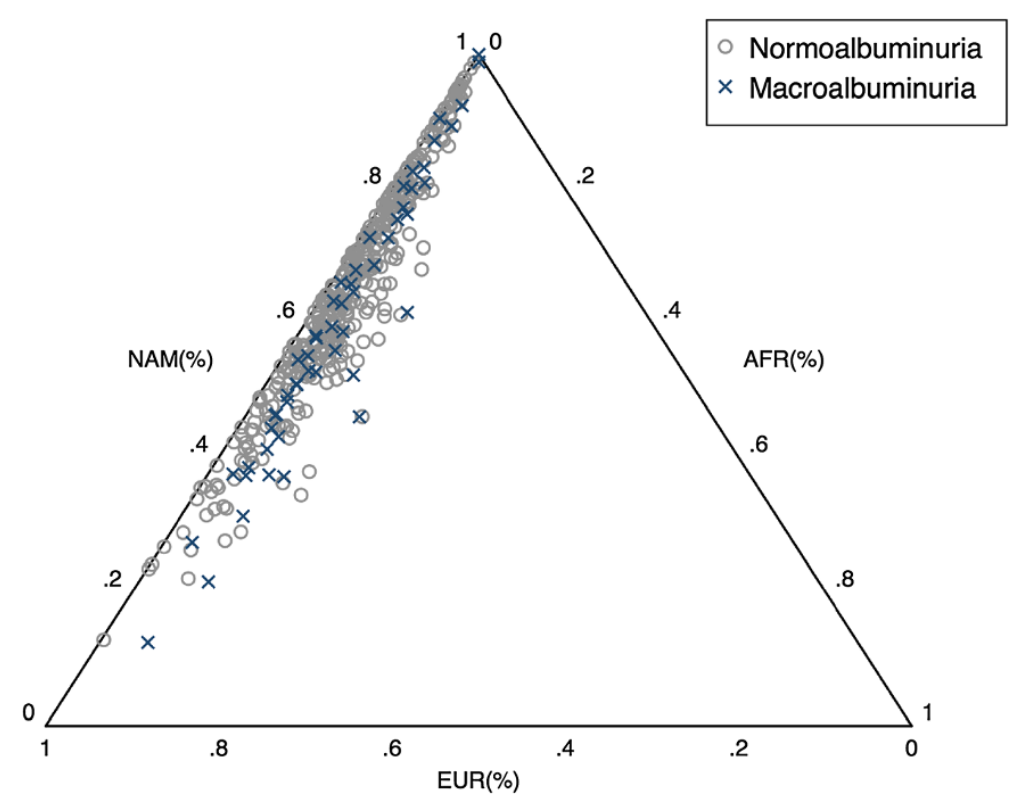

Figure 1 Triangle plot of individual admixture proportions. Triangle plot showing the distribution of the Native American (NAM), the European (EUR) and the African (AFR) individual admixture proportions, in the normoalbuminuric and macroalbuinuric subjects.

against macroalbuminuria. This protective effect has been explained as a result of the conformational change caused by alanine, which increases the efficiency of protein targeting to the mitochondria, thereby leading to a rise of reactive oxygen species scavenging in the mitochondria, and a reduction in glomerular membrane damage due to oxidative stress $[8,9]$.

The contemporary Mexican population is the result of an admixture process that involved Native American, European and African populations. It is well known that the presence of population stratification can inflate the rate of false positives in association studies in admixed populations [28]. For example, when there are substantial differences in admixture proportions between cases and controls, markers showing large frequency differences between the parental populations may be significantly associated with the disease, even if they do not play any causal role. One way to correct for the effects of population stratification is to include individual admixture estimates in the statistical models. Unfortunately, we do not have ancestry estimates for all the individuals included in this sample. However, this information is available for approximately half of the sample, and this gave us the opportunity to explore if the inclusion of admixture estimates in the model may alter the conclusions of our study.

When we restricted our analysis to the participants for which admixture information was available, we observed that macroalbuminuria subjects had a lower Native American ancestry than normoalbuminuria group $(0.597 \pm$ 0.027 vs. $0.663 \pm 0.009, \mathrm{p}=0.012$ ). The odds ratios of the logistic regression analysis incorporating ancestry in the model are similar to those observed in the full sample, again indicating that the $\mathrm{CC}$ and $\mathrm{CT}$ genotypes have a

Table 4 Distribution of the SOD2 gene Val16Ala polymorphism among groups, in albuminuria studies with T2D patients

\begin{tabular}{|c|c|c|c|c|c|c|c|c|c|c|}
\hline \multirow[b]{3}{*}{ Authors (reference) } & \multirow[b]{3}{*}{ Year } & \multirow[b]{3}{*}{ Population } & \multicolumn{4}{|c|}{ Genotype TT/CT/CC } & \multicolumn{4}{|c|}{$\mathrm{C}$ allele frequency } \\
\hline & & & \multicolumn{2}{|c|}{ Macroalbuminuria } & \multicolumn{2}{|c|}{ Normoalbuminuria } & \multirow[b]{2}{*}{ Cases } & \multirow[b]{2}{*}{ Controls } & \multirow[b]{2}{*}{ OR $(95 \% \mathrm{Cl})$} & \multirow[b]{2}{*}{$P$} \\
\hline & & & Number & $P_{\mathrm{HW}}$ & Number & $P_{\mathrm{HW}}$ & & & & \\
\hline Nomiyama (15) & 2003 & Japan & $74 / 14 / 0$ & 1.000 & $206 / 83 / 2$ & 0.038 & 8.0 & 14.9 & $0.49(0.27-0.89)$ & 0.017 \\
\hline Lee (16) & 2006 & Korean & $36 / 4 / 1$ & 0.178 & 203/24/17 & $<0.001$ & 7.3 & 11.9 & $0.59(0.24-1.40)$ & 0.225 \\
\hline Yang (17) & 2007 & Chinese & $47 / 15 / 11$ & 1.000 & $23 / 25 / 2$ & 0.183 & 25.3 & 29.0 & $0.83(0.47-1.47)$ & 0.525 \\
\hline Liu (18) & 2009 & Chinese & $55 / 7 / 0$ & 1.000 & $78 / 22 / 3$ & 0.390 & 5.6 & 13.6 & $0.38(0.16-0.90)$ & 0.023 \\
\hline Ascencio & 2013 & Mexican & $20 / 59 / 40$ & 1.000 & $88 / 400 / 387$ & 0.320 & 58.4 & 63.7 & $0.69(0.52-0.91)$ & 0.008 \\
\hline All studies & & & 232/99/52 & $<0.001$ & $598 / 554 / 411$ & $<0.001$ & 26.5 & 44.0 & $0.65(0.52-0.80)$ & $<0.001$ \\
\hline
\end{tabular}

$P_{H W}$ Hardy-Weinberg equilibrium $\mathrm{P}$ value, $O R$ odds ratio, $C l$ confidence interval, $P$ P value between macroalbuminuric and normoalbuminuric subjects. 


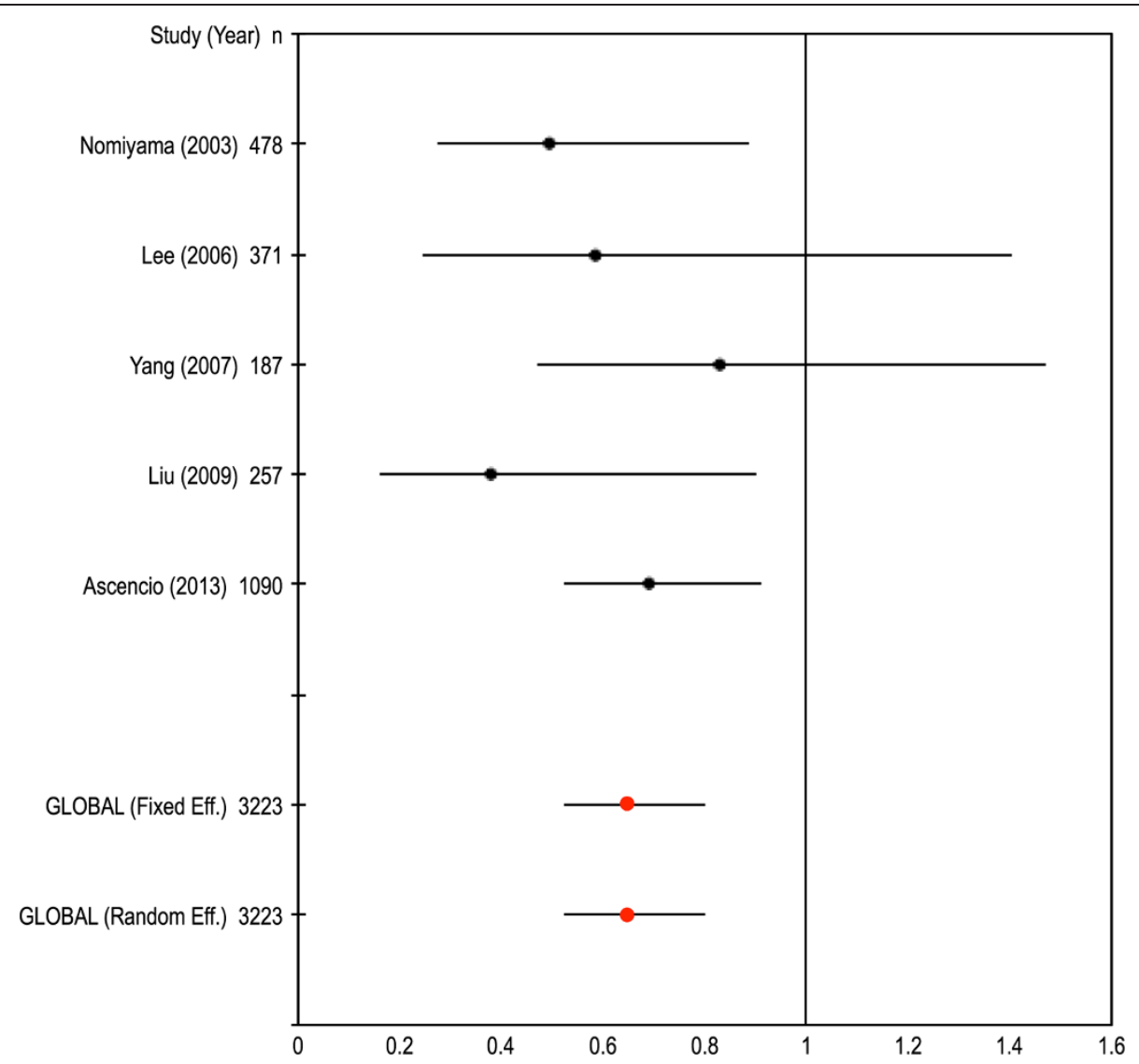

Figure 2 Forest plot of macroalbuminuria and SOD2 gene Val16Ala polymorphism. Forest plot of ORs for macroalbuminuria and SOD2 gene Val16Ala polymorphism in dominant model (CC+TC vs TT) in studies with T2D patients.

protective effect against macroalbuminuria $(\mathrm{CT}: \mathrm{OR}=0.59$, $\mathrm{p}=0.400, \mathrm{CC}: \mathrm{OR}=0.31, \mathrm{p}=0.081$ ). The $\mathrm{p}$-values obtained in this analysis are slightly weaker than in the full sample, but this is not surprising considering that the sample size was reduced in half, with a subsequent reduction in power to identify significant effects. Overall, our data suggests that the significant results observed in the analysis of the full dataset are not due to the presence of population stratification. If stratification was responsible for the results observed in the full sample, we would expect that an analysis of the subsample incorporating ancestry in the statistical models would lead to differences in the ORs observed in both samples. Instead, the ORs are similar in both analyses (in fact, the ORs for the CC and CT genotypes are slightly lower in the model including ancestry than those observed in the full sample, without correction for variation in ancestral proportions). We also estimated the odds ratios restricting the normoalbuminuric sample to subjects with more than 10 years of duration of T2D and the results are very similar to those observed in the full sample.

The allelic frequency of the SOD2 Val16Ala polymorphism risk allele $\mathrm{T}$, which codes for the amino acid valine, in the normoalbuminuric group from Mexico
City is quite similar to the frequencies observed in the HapMap Mexican American sample from Los Angeles, California (32.9\% vs. 36.0\%) (http://hapmap.ncbi.nlm.nih. gov/cgi-perl/snp_details_phase3?name $=$ rs4880\&source $=h$ apmap28_B36\&tmpl=snp_details_phase3). However, the data available for other population groups indicate that there is substantial dispersion of allele frequencies for this polymorphism. For example, in populations from East Asia the frequencies of the $\mathrm{T}$ allele are higher than $85 \%$, and in populations of African and European ancestry, the $\mathrm{T}$ allele has intermediate frequencies, between $50 \%$ and $65 \%$.

In our logistic regression analyses, we included a number of covariates that were significantly associated with macroalbuminuria in our sample (sex, duration of T2D, body mass index, systolic blood pressure, diastolic blood pressure, current or previous smoking, $\mathrm{HbA1c}$, total cholesterol, HDL-cholesterol, LDL-cholesterol, previous diagnosis of hypertension and hypertension treatment). We observed that adding the SOD2 Val16Ala polymorphism to a model including the aforementioned factors increased only slightly the goodness of fit of the model (McFadden's pseudo R2 values increased from 0.361 to 0.369 ). Some of 
the factors identified in our study (male sex, duration of T2D, diastolic blood pressure, HbA1c and LDL cholesterol levels) have also been highlighted in previous studies $[29,30]$. However, in our sample we found that current or previous smoking was inversely associated with macroalbuminuria. This stands in contrast to other studies, in which smoking was found to be a risk factor for DN [29-32], although other studies failed to find associations of smoking and DN $[33,34]$. Unfortunately, we only had information about current or previous tobacco use, and data were not available about duration or intensity of smoking. Other limitations of the study include the lack of information about other microvascular complications such as retinopathy or neuropathy, as well as for other factors that may be important in the pathogenesis of macroalbuminuria, such as practice of regular physical activity, type of diabetes medication, or variation in other enzymatic and nonenzymatic antioxidants. Finally, it is important to note that the sample of macroalbuminuria patients was relatively small (119 individuals). This is related to the low prevalence of macroalbuminuria among T2D patients. For example, De Pablos et al. have reported that the prevalence of macroalbuminuria among T2D patients in a Spanish population was approximately $12 \%$ [35], and in Mexico the prevalence has been estimated between 9 and $10 \%[36,37]$.

\section{Conclusions}

In summary, we show that the SOD2 gene Val16Ala polymorphism is associated with macroalbuminuria. Our results highlight the importance of exploring the effects of polymorphisms located within genes relevant to oxidative stress in order to understand the genetic basis of diabetes complications.

\section{Abbreviations}

ACE: Angiotensin converting enzyme; AFR: African; AlMs: Ancestry Informative Markers; ARB: Angiotensin receptor blockers; Cl: Confidence intervals; DN: Diabetic nephropathy; EUR: European; Hb1Ac: Glycated hemoglobin; IMSS: National Institute of Social Security; MnSOD: Manganese superoxide dismutase; NAM: Native American; RT-PCR: Real-time polymerase chain reaction; SOD2: Superoxide dismutase 2; T2D: Type 2 diabetes.

\section{Competing interests}

The authors declare that they have no competing interests.

\section{Authors' contributions}

IJAM, EJP, AVS, JKR and MC conceived and designed the study. IJAM, AVS, JEP and JHGZ acquired the data. IJAM, EJP, AVS, MC interpreted the data. All authors revised the manuscript for important intellectual content, read, and approved the final manuscript.

\section{Acknowledgements}

We would like to thank to Dr. Laura Cortés Sanabria from Kidney Diseases Medical Research Unit for her useful comments, and to staff of Biochemistry Research Unit for their excellent technical support. This work was supported by the CONACYT SALUD-2005-C02-14412; Proyectos Estratégicos IMSS 20043601-0020; Fundación IMSS, A.C., and the Gonzalo Rio Arronte Foundation. M. Cruz is a recipient of a Fundación IMSS Scholarship.

\section{Author details}

'Biochemistry Research Unit, Hospital de Especialidades, Centro Médico Nacional "Siglo XXI", Instituto Mexicano del Seguro Social, Mexico DF, Mexico. ${ }^{2}$ Department of Anthropology, University of Toronto at Mississauga, Mississauga, Ontario, Canada. ${ }^{3}$ Fundación IMSS, Mexico DF, Mexico. ${ }^{4}$ Clinical Epidemiology Research Unit, Hospital General Regional No. 1 "Carlos MacGregor Sánchez Navarro", Instituto Mexicano del Seguro Social, Mexico DF, Mexico.

Received: 1 August 2013 Accepted: 1 October 2013

Published: 11 October 2013

\section{References}

1. American Diabetes Association: Diabetic nephropathy. Diabetes Care 2000, 23(Suppl 1):S69-S72.

2. Ayodele OE, Alebiosu CO, Salako BL: Diabetic nephropathy-a review of the natural history, burden, risk factors and treatment. J Natl Med Assoc 2004, 11:1445-1454.

3. Forbes $\mathrm{JM}$, Coughlan MT, Cooper ME: Oxidative stress as a major culprit in kidney disease in diabetes. Diabetes 2008, 6:1446-1454.

4. Viana LV, Gross JL, Camargo JL, Zelmanovitz T, da Costa Rocha EP, Azevedo MJ: Prediction of cardiovascular events, diabetic nephropathy, and mortality by albumin concentration in a spot urine sample in patients with type 2 diabetes. J Diabetes Complications 2012, 5:407-4012.

5. Berhane AM, Weil EJ, Knowler WC, Nelson RG, Hanson RL: Albuminuria and estimated glomerular filtration rate as predictors of diabetic end-stage renal disease and death. Clin J Am Soc Nephrol 2011, 10:2444-2451.

6. MacLeod JM, Lutale J, Marshall SM: Albumin excretion and vascular deaths in NIDDM. Diabetologia 1995, 5:610-616.

7. Fukai T, Ushio-Fukai M: Superoxide dismutases: role in redox signaling, vascular function and diseases. Antioxid Redox Signal 2011, 6:1583-1606.

8. Sutton A, Khoury H, Prip-Buus C, Cepanec C, Pessayre D, Degoul F: The Ala16Val genetic dimorphism modulates the import of human manganese superoxide dismutase into rat liver mitochondria. Pharmacogenetics 2003, 3:145-157.

9. Shimoda-Matsubayashi S, Matsumine H, Kobayashi T, Nakagawa-Hattori $Y$, Shimizu Y, Mizuno Y: Structural dimorphism in the mitochondrial targeting sequence in the human manganese superoxide dismutase gene. A predictive evidence for conformational change to influence mitochondrial transport and a study of allelic association in Parkinson's disease. Biochem Biophys Res Commun 1996, 2:561-565.

10. Karter AJ, Ferrara A, Liu JY, Moffet HH, Ackerson LM, Selby JV: Ethnic disparities in diabetic complications in an insured population. JAMA 2002, 19:2519-2527.

11. Smith $S R$, Svetkey $L P$, Dennis WW: Racial differences in the incidence and progression of renal diseases. Kidney Int 1991, 5:815-822.

12. Young BA, Maynard C, Boyko EJ: Racial differences in diabetic nephropathy, cardiovascular disease, and mortality in a national population of veterans. Diabetes Care 2003, 8:2392-2399.

13. Bryson CL, Ross HJ, Boyko EJ, Young BA: Racial and ethnic variations in albuminuria in the US Third National Health and Nutrition Examination Survey (NHANES III) population: associations with diabetes and level of CKD. Am J Kidney Dis 2006, 5:720-726.

14. Martinez-Marignac VL, Valladares A, Cameron E, Chan A, Perera A, GlobusGoldberg R, Wacher N, Kumate J, McKeigue P, O'Donnell D, Shriver MD, Cruz $M$, Parra E: Admixture in Mexico City: implications for admixture mapping of type 2 diabetes genetic risk factors. Hum Genet 2007, 6:807-819.

15. Nomiyama T, Tanaka Y, Piao L, Nagasaka K, Sakai K, Ogihara T, Nakajima K, Watada H, Kawamori R: The polymorphism of manganese superoxide dismutase is associated with diabetic nephropathy in Japanese type 2 diabetic patients. J Hum Genet 2003, 3:138-141.

16. Lee SJ, Choi MG, Kim DS, Kim TW: Manganese superoxide dismutase gene polymorphism (V16A) is associated with stages of albuminuria in Korean type 2 diabetic patients. Metabolism 2006, 1:1-7.

17. Yang $Y$, Song D, Wang $Y$, Yang $K$, Tan D, Liu H, Duan Y, Zhang M: Association between manganese superoxide dismutase gene V16A polymorphism and type 2 diabetic nephropathy. Chin J Diabetes 2007, 1:18-20.

18. Liu L, Zheng T, Wang N, Wang F, Li M, Jiang J, Zhao R, Li L, Zhao W, Zhu Q, Jia W: The manganese superoxide dismutase Val16Ala polymorphism is 
associated with decreased risk of diabetic nephropathy in Chinese patients with type 2 diabetes. Mol Cell Biochem 2009, 1-2:87-91.

19. Tian C, Fang S, Du X, Jia C: Association of the C47T polymorphism in SOD2 with diabetes mellitus and diabetic microvascular complications: a meta-analysis. Diabetologia 2011, 4:803-811.

20. American Diabetes Association: Standards of medical care in diabetes2013. Diabetes Care 2013, 36(Suppl 1):S11-S66.

21. KDOQI: KDOQI Clinical practice guidelines and clinical practice recommendations for diabetes and chronic kidney disease. Am J Kidney Dis 2007, 49(2):S12-S154

22. Alexander DH, Novembre J, Lange K: Fast model-based estimation of ancestry in unrelated individuals. Genome Res 2009, 9:1655-1664.

23. Parra EJ, Below JE, Krithika S, Valladares A, Barta JL, Cox NJ, Hanis CL, Wacher N, Garcia- Mena J, Hu P, Shriver MD; Diabetes Genetics Replication and Meta-analysis (DIAGRAM) Consortium, Kumate J, McKeigue PM, Escobedo J, Cruz M: Genome-wide association study of type 2 diabetes in a sample from Mexico City and a meta-analysis of a Mexican-American sample from Starr County, Texas. Diabetologia 2011, 8:2038-2046.

24. Arredondo A, Zuñiga A: Economic consequences of epidemiological changes in diabetes in middle-income countries: the Mexican case. Diabetes Care 2004, 1:104-109.

25. Niedowicz DM, Daleke DL: The role of oxidative stress in diabetic complications. Cell Biochem Biophys 2005, 2:289-330.

26. Palomo-Piñon S, Gutierrez-Rodriguez ME, Diaz-Flores M, Sanchez-Barrera R, Valladares-Salgado A, Utrera-Barillas D, Duran-Reyes G, Galvan-Duarte RE, Trinidad-Ramos P, Cruz M: DD genotype of angiotensin-converting enzyme in type 2 diabetes mellitus with renal disease in Mexican Mestizos. Nephrology (Carlton) 2009, 2:235-239.

27. Parra EJ, Cruz M, Gomez-D'az R, Utrera-Barillas D, Garcia-Mena J, Rosas M, Valladares-Salgado A, Angeles-Martinez J, Escobedo-de la Pena J: Association of polymorphisms within the transforming growth factor- $\beta 1$ gene with diabetic nephropathy and serum cholesterol and triglyceride concentrations. Nephrology (Carlton) 2010, 6:644-648.

28. Hoggart CJ, Parra EJ, Shriver MD, Bonilla C, Kittles RA, Clayton DG, McKeigue PM: Control of confounding of genetic associations in stratified populations. Am J Hum Genet 2003, 6:1492-1504.

29. Retnakaran R, Cull CA, Thorne Kl, Adler Al, Holman RR: UKPDS Study group: risk factors for renal dysfunction in type 2 diabetes: U.K. prospective diabetes study. Diabetes 2006, 6:1832-1839.

30. Coll-de-Tuero G, Mata-Cases M, Rodriguez-Poncelas A, Pepió JM, Roura P, Benito B, Franch-Nadal J, Saez M: Chronic kidney disease in the type 2 diabetic patients: prevalence and associated variables in a random sample of 2642 patients of a Mediterranean area. BMC Nephrol 2012, 13(1):87.

31. Forsblom CM, Groop PH, Ekstrand A, Tötterman KJ, Sane T, Saloranta C, Groop L: Predictors of progression from normoalbuminuria to microalbuminuria in NIDDM. Diabetes Care 1998, 11:1932-1938.

32. Sawicki PT, Didjurgeit U, Mühlhauser I, Bender R, Heinemann L, Berger M: Smoking is associated with progression of diabetic nephropathy. Diabetes Care 1994, 2:126-131.

33. Smulders YM, Rakic M, Stehouwer CD, Weijers RN, Slaats EH, Silberbusch J: Determinants of progression of microalbuminuria in patients with NIDDM.A prospective study. Diabetes Care 1997, 6:999-1005

34. Gall MA, Hougaard P, Borch-Johnsen K, Parving HH: Risk factors for development of incipient and overt diabetic nephropathy in patients with non-insulin dependent diabetes mellitus: prospective, observational study. BMJ 1997, 7083:783-788

35. De Pablos PL, Martinez J, Martinez MP, Doreste JA: Prevalence of microand macroalbuminuria in a Canarian population of type 2 diabetic patients. Relationship with blood pressure, lipid profile, obesity and metabolic control. Diabetes Metab 1998, 4:337-343.

36. Cueto-Manzano AM, Cortes-Sanabria L, Martinez-Ramirez HR, Rojas-Campos E, Barragan G, Alfaro G, Flores J, Anaya M, Canales-Munoz JL: Detection of early nephropathy in Mexican patients with type 2 diabetes mellitus. Kidney Int Supp/ 2005, 97:S40-S45.
37. Escobedo J, Rana JS, Lombardero MS, Albert SG, Davis AM, Kennedy FP, Mooradian AD, Robertson DG, Srinivas VS, Gebhart SS: Study Group: association between albuminuria and duration of diabetes and myocardial dysfunction and peripheral arterial disease among patients with stable coronary artery disease in the BARI 2D study. Mayo Clin Proc 2010, 1:41-46.

doi:10.1186/1471-2350-14-110

Cite this article as: Ascencio-Montiel et al:: SOD2 gene Val16Ala polymorphism is associated with macroalbuminuria in Mexican Type 2 Diabetes patients: a comparative study and meta-analysis. BMC Medical Genetics 2013 14:110.

\section{Submit your next manuscript to BioMed Central and take full advantage of:}

- Convenient online submission

- Thorough peer review

- No space constraints or color figure charges

- Immediate publication on acceptance

- Inclusion in PubMed, CAS, Scopus and Google Scholar

- Research which is freely available for redistribution

Submit your manuscript at www.biomedcentral.com/submit
C) Biomed Central 